\title{
Effects of excess cadmium in soil on JIP-test parameters, hydrogen peroxide content and antioxidant activity in two maize inbreds and their hybrid
}

\author{
M. FRANIĆ ${ }^{+}$, V. GALIĆ, M. MAZUR, and D. ŠIMIĆ \\ Agricultural Institute Osijek, Department of Maize Breeding and Genetics, HR31103, Južno predgrađe 17 Osijek, Croatia
}

\begin{abstract}
Excessive cadmium $(\mathrm{Cd})$ content in soil leads to a number of phytotoxic effects and challenges agricultural production. Aim of this study was to investigate different responses of two maize inbreds and their hybrid to an elevated Cd content in soil by measuring photosynthetic and biochemical activity and to identify a Cd tolerance mechanism. Antioxidant statusrelated parameters varied significantly between inbreds and treatments. Dry mass increased in both inbreds, but remained unchanged in hybrid. After the Cd treatment, parameters of chlorophyll $a$ fluorescence varied between inbreds and hybrid performance was similar to inbred B84. We concluded that inbred B84 is Cd-sensitive compared to Os6-2, which did not appear to be negatively affected by $\mathrm{Cd}$ treatment at this growth stage studied. We suspect that due to a dilution effect in the hybrid, there was no or very weak Cd stress detected by biochemical parameters, although stress was detected by chlorophyll $a$ fluorescence.
\end{abstract}

Additional key words: antioxidant enzymes; heavy metal toxicity; JIP test; photosynthesis; photosystem II.

\section{Introduction}

Cadmium is a trace element known for its adverse effects in cellular systems of plants and animals. Once taken in by the plant, it causes damage in a number of molecular mechanisms and cell compartments (Das et al. 1998). Visual symptoms of Cd phytotoxicity include chlorosis, reduction of growth, leaf rolling, browning of root tips, and death in some cases. Key sources of excess $\mathrm{Cd}$ concentrations in soils are antropogenic activities, such as traffic, industry, and application of phosphate fertilizers (Di Toppi and Gabbrielli 1999). Its uptake by roots is mostly a transpiration driven passive process; plants possess no Cd-exclusion mechanism (Gallego et al. 2012). Other mechanism for $\mathrm{Cd}$ to enter plant cell is through the transport systems involved in micronutrient uptake, specifically through transmembrane divalent metal carriers although there is no evidence that these transporters can transport $\mathrm{Cd}$ above $\mathrm{Fe}$ (Verbruggen et al. 2009). Cd causes oxidative stress in plants by altering activities of antioxidant defense mechanisms resulting in hydrogen peroxide accumulation (Sandalio et al. 2001, Schützendübel and Polle 2002, Cho and Seo 2005) which eventually leads to an increase of protein (Romero-Puertas et al. 2002) and lipid peroxidation (Chaoui et al. 1997). Mechanisms that cope with elevated contents of hydrogen peroxide either catalyze its decomposition into oxygen and water or use substrate to reduce peroxide thus producing

Received 17 November 2016, accepted 19 January 2017, published as online-first 13 March 2017.

${ }^{+}$Corresponding author; e-mail: mario.franic@poljinos.hr

Abbreviations: ABS/RC - absorption per active reaction centre; APX - ascorbate peroxidase; Car - carotenoids; CAT - catalase; Chl chlorophyll; CK - control; DIo/RC - dissipation per active reaction centre; DM - dry mass; FM - fresh mass; ET - electron transport; $\mathrm{ET}_{\mathrm{o}} / \mathrm{ABS}$ - quantum yield for electron transport; $\mathrm{ET}_{0} / \mathrm{RC}$ - electron transport per active reaction centre; $\mathrm{ET}_{\mathrm{o}} / \mathrm{TR}_{\mathrm{o}}$ - efficiency/probability for electron transport; $\mathrm{ET}_{\mathrm{o}}\left(\mathrm{TR}_{\mathrm{o}}-\mathrm{ET}_{\mathrm{o}}\right)$ - electron transport beyond $\mathrm{Q}_{\mathrm{A}}^{-} ; \mathrm{F}_{0}-$ minimal fluorescence yield of the dark-adapted state; $\mathrm{F}_{\mathrm{m}}$ - maximal fluorescence yield of the dark-adapted state; $F_{v}$ - variable fluorescence; $F_{v} / F_{m}$ - maximal quantum yield of PSII photochemistry; $\mathrm{M}_{\mathrm{o}}$ - approximated initial slope $\left(\mathrm{ms}^{-1}\right)$ of the fluorescence transient normalised on the maximal variable fluorescence $\mathrm{F}_{\mathrm{v}} ; \mathrm{PI}_{\mathrm{ABS}}$ - performance index (potential) for energy conservation from exciton to the reduction of intersystem electron acceptors; POD - peroxidase; RC/ABS - density of reaction centres on chlorophyll $a$ basis; $\mathrm{RC} / \mathrm{CS}_{\mathrm{o}}$ - density of reaction centres per excited cross section; ROS - reactive oxygen species; $\mathrm{S}_{\mathrm{m}}$ - normalised total complementary area above the transient curve; TBARS - thiobarbituric acid-reactive substances; $t_{\max }$ - time (in $\mathrm{ms}$ ) to reach the maximal fluorescence intensity $\mathrm{F}_{\mathrm{m}}$; $\mathrm{TR}_{\mathrm{o}} / \mathrm{ABS}$ - maximum quantum yield for primary photochemistry; $\mathrm{TR}_{0} / \mathrm{DI}_{0}$ - flux ratio trapping per dissipation; $\mathrm{TR}_{0} / \mathrm{RC}$ - trapping per active reaction centre; $\mathrm{V}_{\mathrm{J}}-$ relative variable fluorescence at $\mathbf{J}$ step.

Acknowledgements: This research was funded by the Croatian Science Foundation (project No. 5707: „Genetics and physiology of multiple stress tolerance in maize"). 
water and oxidized substrate. Enzymes that perform these actions are catalase (CAT), peroxidase (POD), and ascorbate peroxidase (APX), while pigments from group of carotenoids (Car) act as nonenzymatic reactive oxygen species (ROS) quenchers (Anjum et al. 2015). Cd can also affect reduction of $\mathrm{CO}_{2}$ fixation (Weigel 1985) and it is most probably due to modulation of key carboxylating enzymes of Calvin cycle, i.e. Rubisco and phosphoenolpyruvate carboxylase (PEPC) (Krantev et al. 2008).

$\mathrm{Cd}$ can even substitute the central $\mathrm{Mg}$ atom of chlorophyll $(\mathrm{Chl})$ and this results in a breakdown of photosynthesis (Küpper et al. 1996). Every environmental change forces the photosynthetic apparatus to adjust its physiological state; parameters of fast polyphasic fluorescence induction transient appear to change accordingly (Strasser et al. 2004). Saturating light presents an energy influx to a dark-adapted photosynthetic apparatus, with one of its output being fluorescence along with dissipation in terms of heat. Measurement of fluorescence induction transients in dark-adapted samples spans for $1 \mathrm{~s}$ with datapoint resolution of $10 \mu$ s and a key state identified as $F_{0}$ (initial fluorescence intensity) and $\mathrm{F}_{\mathrm{m}}$ (maximal intensity) (Strasser et al. 2004). Between these two extrema, intermediate time-steps, such as $\mathrm{K}$ (at $300 \mu \mathrm{s})$, J (at $2 \mathrm{~ms}$ ), and I (at $30 \mathrm{~ms}$ ) (Fig. 1) related to electron flux between

\section{Materials and methods}

Plant materials and growth conditions: Seeds of two maize (Zea mays L.) genotypes with different sensitivity to $\mathrm{Cd}$ in soil along with their hybrid were planted in trays $(21 \times 35 \times 7 \mathrm{~cm})$ filled with universal substrate and placed in a growth chamber $\left[25^{\circ} \mathrm{C}, 16 / 8\right.$ day/night, $200 \mu \mathrm{mol}$ (photon) $\mathrm{m}^{-2} \mathrm{~s}^{-1}$. Line B84 is a public line of Iowa Stiff Stalk Synthetic (BSSS) related to well-known reference line B73, while Os6-2 is a Lancaster inbred line related to line $\mathrm{C} 103$ and reference line Mo17, classified into two respective heterotic groups (Lee and Tracy 2009). Substrate properties were: nitrogen $\left(\mathrm{NH}_{3}+\mathrm{NO}^{3-}\right)$ at $70 \mathrm{mg} \mathrm{L}^{-1}$, phosphorous $\left(\mathrm{P}_{2} \mathrm{O}_{5}\right)$ at $80 \mathrm{mg} \mathrm{L}^{-1}$, potassium $\left(\mathrm{K}_{2} \mathrm{O}\right)$ of $90 \mathrm{mg} \mathrm{L}^{-1}$, organic matter of $70 \%$ (dry mass, DM), and pH $5.7\left(\mathrm{CaCl}_{3}\right)$. Contents of heavy metals $(\mathrm{Cd}, \mathrm{Cr}, \mathrm{Cs}, \mathrm{Hg}$, $\mathrm{Ni}, \mathrm{Pb}, \mathrm{Zn}$ ) and other toxic substances (polycyclic aromatic hydrocarbons, polychlorinated biphenyls) were below permitted amounts; Cd content was $0.2 \mathrm{mg} \mathrm{kg}^{-1}$ (soil $\mathrm{DM})$. Total of 42 seeds were planted in one tray for each genotype for treatment and control (CK). Seeds $(n=42)$ were planted in a tray for each genotype, $\mathrm{CK}$ and $\mathrm{Cd}$ treatment were considered one replicate. Experiment was set in three replicates. Soil for CK was left uncontaminated and for the Cd treatment (Cd5) with $5 \mathrm{mg}(\mathrm{Cd}) \mathrm{kg}^{-1}$ (soil), soil was weighed and spread in approximately $5-\mathrm{cm}$ thick layer and sprayed with a solution of $\mathrm{CdCl}_{2} \cdot \mathrm{CdCl}_{2}$ solution was made by dissolving $4.0805 \mathrm{~g}$ of $\mathrm{CdCl}_{2}$ in $5 \mathrm{~L}$ of deionized water. For $\mathrm{Cd} 5$ treatment, $10 \mathrm{~mL}$ of prepared solution was sprayed using a spray bottle for every $\mathrm{kg}$ of soil. During the spraying of the solution, soil was mixed
PSII components, can be observed and measuring these states resembles informative O-J-I-P curve (Strasser et al. 1995). Chl $a$ fluorescence measurement is a suitable method for detection and evaluation of heavy metal stresses (Żurek et al. 2014) and it is sensitive to Cd stress (Larsson et al. 1998, Di Cagno et al. 1999, Burzyński and Żurek, 2007). Chl $a$ measurements yield a large number of parameters that can be used to interpret the state of photosystems, such as experimental and normalized signals $\left(\mathrm{F}_{\mathrm{o}}, \mathrm{F}_{\mathrm{m}}, \mathrm{F}_{\mathrm{v}}, \mathrm{F}_{\mathrm{v}} / \mathrm{F}_{\mathrm{m}}\right)$ as shown by Tuba et al. (2010) on bryophytes or transient fluorescence curves and phenomenological energy fluxes as shown on barley seedlings (Kalaji et al. 2007). There is a significant variation in affinity for heavy metals accumulation among as well as within plant species (Grant et al. 1998). Maize inbreds have been shown to differ in uptake of heavy metals (Florijn and van Beusichem 1993, Brkić et al. 2003) and temperate inbred lines, B84 and Os6-2, have been designated as different according to their respective ionomic profiles (Sorić et al. 2011, Šimić et al. 2012) and leaf Cd accumulation (Sorić et al. 2009).

The aim of our study was to evaluate effects of excessive $\mathrm{Cd}$ content in soil on young plants of maize inbred lines B84 and Os6-2 and their respective hybrid by means of Chl $a$ fluorescence and activity of antioxidant enzymes.

multiple times. Trays were watered with $200 \mathrm{~mL}$ of water every two days. Plantlets were grown for ten days after planting and on the last day, Chl $a$ fluorescence measurements using the fluorimeter Handy PEA (Hansatech, King's Lynn UK) were performed after which leaves were cut and stored in the freezer $\left(-80^{\circ} \mathrm{C}\right)$ until further analysis.

Chl $\boldsymbol{a}$ fluorescence was measured on the middle section of the first fully developed leaf; 15 measurements per replicate (tray) were performed giving a total of 45 measurements for each genotype per treatment. After dark adaptation for $30 \mathrm{~min}$, Chl fluorescence transient was induced by applying a pulse of saturating red light [peak at $650 \mathrm{~nm}, 3,200 \mu \mathrm{mol}$ (photon) $\mathrm{m}^{-2} \mathrm{~s}^{-1}$ ] on the leaf surface which was exposed by the leaf clip (4 $\mathrm{mm}$ in diameter). Saturating-light pulse induced fluorescence increase from minimal fluorescence $\left(\mathrm{F}_{\mathrm{o}}\right)$, when all reaction centers are open, to maximal fluorescence $\left(\mathrm{F}_{\mathrm{m}}\right)$, when all reaction centers are closed. During the 1-s measurement, 120 data points were collected. Chl $a$ fluorescence data were processed with software provided with the fluorimeter.

Data obtained by Chl $a$ fluorescence measurements was analyzed according to the JIP-test that outputs multiple parameters quantifying the photochemistry of PSII. The JIP-test was described by Strasser et al. (1995, 2004, 2010). JIP-test parameters are listed in Fig. 2, for definitions and formulas see Table $2 \mathrm{~S}$ (supplement avaliable online). 
Photosynthetic pigments and DM analysis: Collected samples of frozen leaves were powdered in a porcelain mortar in liquid nitrogen with addition of magnesium hydroxide carbonate. A sample (1 g) was put in an Eppendorf tube with $1 \mathrm{~mL}$ of cold acetone and vortexed. Tubes were placed on ice for $15 \mathrm{~min}$, centrifuged for $10 \mathrm{~min}$ at $4^{\circ} \mathrm{C}$ and $20,000 \times g$. Precipitate was reextracted with the same procedure until the tissue lost its color. Concentration of photosynthetic pigments (Chl $a, b$, and Car) was determined spectrophotometrically (Specord 200, Analytik, Jena, Germany) according to Lichtenthaler (1987) with absorbance readings at 470,661.6, and $664.8 \mathrm{~nm}$ in a glass cuvette. Acetone was used as blank.

Percentage of leaf dry mass (DM) was determined by weighing $1 \mathrm{~g}$ of ground fresh sample (ground in liquid nitrogen) in an Eppendorf tube and drying at $105^{\circ} \mathrm{C}$ for $48 \mathrm{~h}$. Dry mass (DM) is expressed as \% of fresh mass (FM). Three samples of pigments and DM were measured for each treatment, genotype, and replicate.

Assays of antioxidant enzymes activity, $\mathrm{H}_{2} \mathrm{O}_{2}$ concentration and TBARS content

Enzyme extractions: Tissue was macerated into fine powder in liquid nitrogen using mortar and pestle with the addition of polyvinylpyrrolidone (PVP). Approximately $0.2 \mathrm{~g}$ of powdered tissue was extracted for $15 \mathrm{~min}$ on ice with $1 \mathrm{~mL}$ of extraction buffer (for APX: $100 \mathrm{mM}$ potassium phosphate buffer $\mathrm{pH} 7.0+5 \mathrm{mM} \mathrm{Na}$-ascorbate + $1 \mathrm{mM}$ EDTA, for CAT and guaiacol peroxidase: $100 \mathrm{mM}$ potassium phosphate buffer $\mathrm{pH}$ 7.0). Afterwards it was centrifuged at $18,000 \times g$ for $10 \mathrm{~min}$ at $4^{\circ} \mathrm{C}$ and supernatants were taken for APX, CAT, and guaiacol POD. Activities were measured spectrophotometrically using spectrophotometer (Specord 200, Analytik, Jena, Germany).

Antioxidant enzyme activities: Ascorbate peroxidase (APX; EC 1.11.1.11) activity was determined according to Nakano and Asada (1981) by monitoring the decrease in absorbance at $290 \mathrm{~nm}$ due to ascorbate oxidation $(\varepsilon=2.8$ $\mathrm{mM}^{-1} \mathrm{~cm}^{-1}$ ) during $2 \mathrm{~min}$. Reaction mixture consisted of $50 \mathrm{mM}$ potassium phosphate buffer $(\mathrm{pH}=7.0)$ with $0.1 \mathrm{mM}$ EDTA, $50 \mathrm{mM}$ ascorbic acid, and sample extract. Reaction was started by adding $10 \mu \mathrm{L}$ of $12 \mathrm{mM} \mathrm{H}_{2} \mathrm{O}_{2}$ to $990 \mu \mathrm{L}$ of the reaction mixture. Enzyme activity was expressed as $\mu \mathrm{M}$ (ascorbate oxidized) $\mathrm{min}^{-1} \mathrm{~g}^{-1}$ (FM). Catalase (CAT; EC 1.11.1.6) activity was determined according to Aebi (1984) by monitoring the decrease in absorbance due to decomposition of $\mathrm{H}_{2} \mathrm{O}_{2}$ at $240 \mathrm{~nm}\left(\varepsilon=0.036 \mathrm{mM}^{-1} \mathrm{~cm}^{-1}\right)$ during $1 \mathrm{~min}$. Reaction was started with addition of sample extract to reaction mixture consisting of $50 \mathrm{mM}$ potassium phosphate buffer $(\mathrm{pH}=7)$ with $10 \mathrm{mM} \mathrm{H}_{2} \mathrm{O}_{2}$. Enzyme activity was expressed as $\mu \mathrm{M}\left(\mathrm{H}_{2} \mathrm{O}_{2}\right.$ decomposed $) \mathrm{min}^{-1} \mathrm{~g}^{-1}(\mathrm{FM})$.

\section{Results}

PSII parameters derived by the JIP-test: Selected parameters of $\mathrm{Chl} a$ fluorescence and parameters derived by
Guaiacol peroxidase (POD; EC 1.11.1.7) activity was measured according to Siegel and Galston (1967). POD activity was determined by monitoring the increase in absorbance due to guaiacol oxidation $\left(\varepsilon=26.1 \mathrm{mM}^{-1} \mathrm{~cm}^{-1}\right)$ at $470 \mathrm{~nm}$ over $2 \mathrm{~min}$. Reaction mixture consisted of $5 \mathrm{mM}$ guaiacol and $5 \mathrm{mM} \mathrm{H}_{2} \mathrm{O}_{2}$ in $0.2 \mathrm{mM}$ phosphate buffer (pH 5.8). Reaction was started by adding protein extract to reaction mixture. Enzyme activity was calculated as $\mu \mathrm{M}$ (guaiacol oxidized) $\min ^{-1} \mathrm{~g}^{-1}(\mathrm{FM})$.

$\mathrm{H}_{2} \mathrm{O}_{2}$ concentration was determined according to Velikova et al. (2000). Approximately $0.2 \mathrm{~g}$ of leaf tissue was powdered in liquid nitrogen and extracted with $2 \mathrm{~mL}$ of $0,1 \%$ trichloroacetic acid (TCA) on ice for $10 \mathrm{~min}$. After the extraction, aliquot was centrifuged at $14,000 \times g$ for $15 \mathrm{~min}$ at $4^{\circ} \mathrm{C}$. The supernatant of $400 \mu \mathrm{L}$ was transfered to a new Eppendorf tube and mixed with $600 \mu \mathrm{L}$ of $10 \mathrm{mM}$ potassium phosphate buffer and $1 \mathrm{~mL}$ of $1 \mathrm{M}$ potassium iodide. This reaction mixture was vortexed and left in the dark for $20 \mathrm{~min}$. Absorbance was measured at $390 \mathrm{~nm}$ and $1 \mathrm{ml}$ of $10 \mathrm{mM}$ potassium phosphate buffer $+1 \mathrm{~mL} 1 \mathrm{M}$ potassium iodide was used as blank. $\mathrm{H}_{2} \mathrm{O}_{2}$ concentration was calculated using samples absorbance values from the standard curve and expressed as $\mu \mathrm{mol} \mathrm{g}^{-1}(\mathrm{FM})$.

TBARS content was determined according to Verma and Dubey (2003). Samples were powdered in liquid nitrogen and extracted with $1 \mathrm{~mL}$ of $0.1 \%(\mathrm{w} / \mathrm{v})$ TCA. After centrifugation at $6,000 \times g$ for $5 \mathrm{~min}, 0.5 \mathrm{~mL}$ of the supernatant was added to $1 \mathrm{~mL}$ of $0.5 \%(\mathrm{w} / \mathrm{v})$ thiobarbituric acid (TBA) in $20 \%$ TCA. The mixture was heated at $95^{\circ} \mathrm{C}$ for $30 \mathrm{~min}$, then quickly cooled in an ice-bath and centrifuged at $18,000 \times g$ for $15 \mathrm{~min}$ at $4^{\circ} \mathrm{C}$. The TBARS content was determined by measuring absorbance at 532 and $600 \mathrm{~nm}$. The concentration of lipid peroxidation products was expressed as total TBARS in terms of $\mathrm{nmol}^{-1}(\mathrm{FM})$, using an extinction coefficient of $155 \mathrm{mM}^{-1} \mathrm{~cm}^{-1}$.

Statistical analysis was performed using $R$ ( $R$ Core Team, 2012). Analysis of variance ( $A N O V A$ ) function from R's car package was used for factorial ANOVA with three sources of variation: treatment, genotype, and replication. Statistical Tool for Agricultural Research (STAR 2014) was used to calculate Tukey's honest significant difference (HSD) test at $P<0.05$ level $\left(\mathrm{HSD}_{0.05}\right)$. Measurements $(n=15)$ of Chl $a$ fluorescence were performed per replicate. For antioxidant enzymes, TBARS, $\mathrm{H}_{2} \mathrm{O}_{2}$, pigments, and DM, 3 samples per replicate were measured. Since there were no significant differences between replicates, all $\mathrm{Chl}$ $a$ fluorescence $(n=45)$ and biochemical analyses $(n=9)$ data were pooled to produce test statistics for graphs.

the JIP-test are shown in Figs. 1 and 2. In order to compare genotypes, values of parameters were normalized to their 


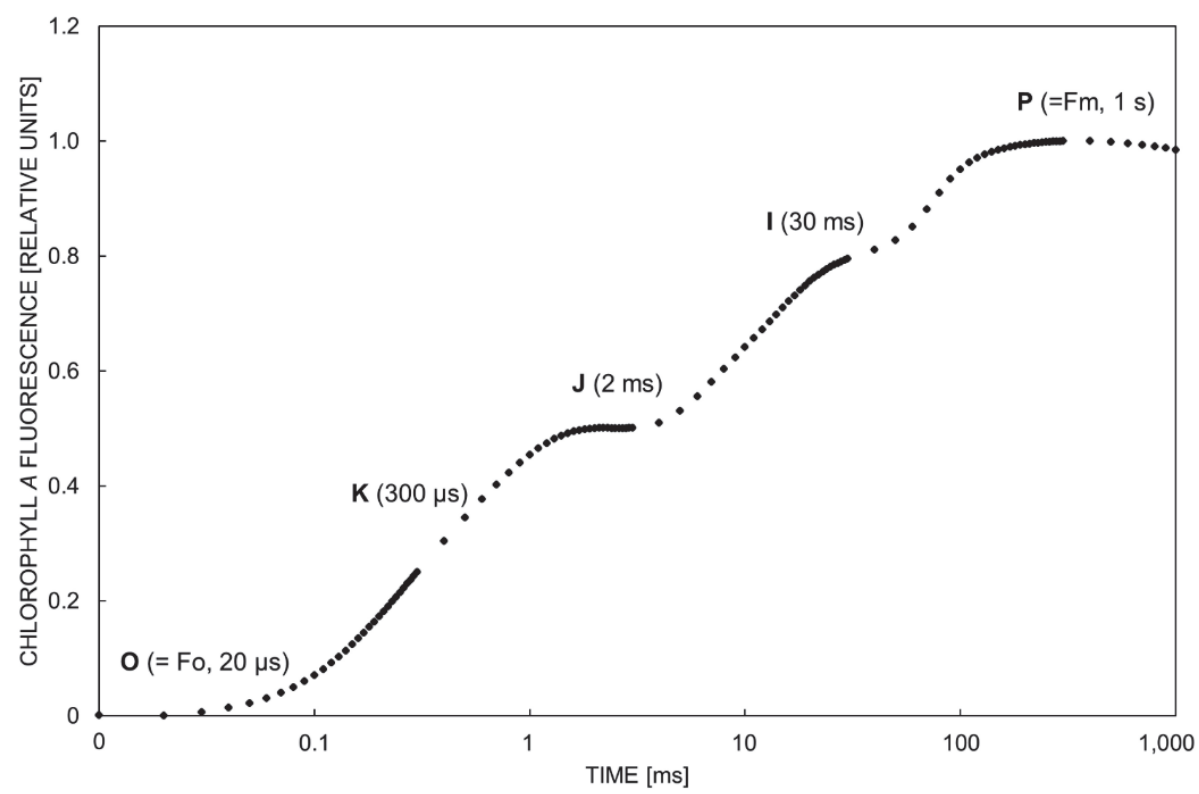

Fig. 1.Typical OJIP transient of chlorophyll fluorescence obtained by illumination of a dark-adapted leaf sample by saturating red light. Transient is plotted on a logarithmic time scale ( $20 \mathrm{~ms}$ to $1 \mathrm{~s}$ ). Symbols O, K, J, I, P represent fluorescence intensities at $50 \mu \mathrm{s}, 300 \mu \mathrm{s}$, $2 \mathrm{~ms}$, and $300 \mathrm{~ms}$, respectively. The figure was created using data measured with the fluorimeter Handy PEA (Hansatech, King's Lynn UK) on maize leaf.

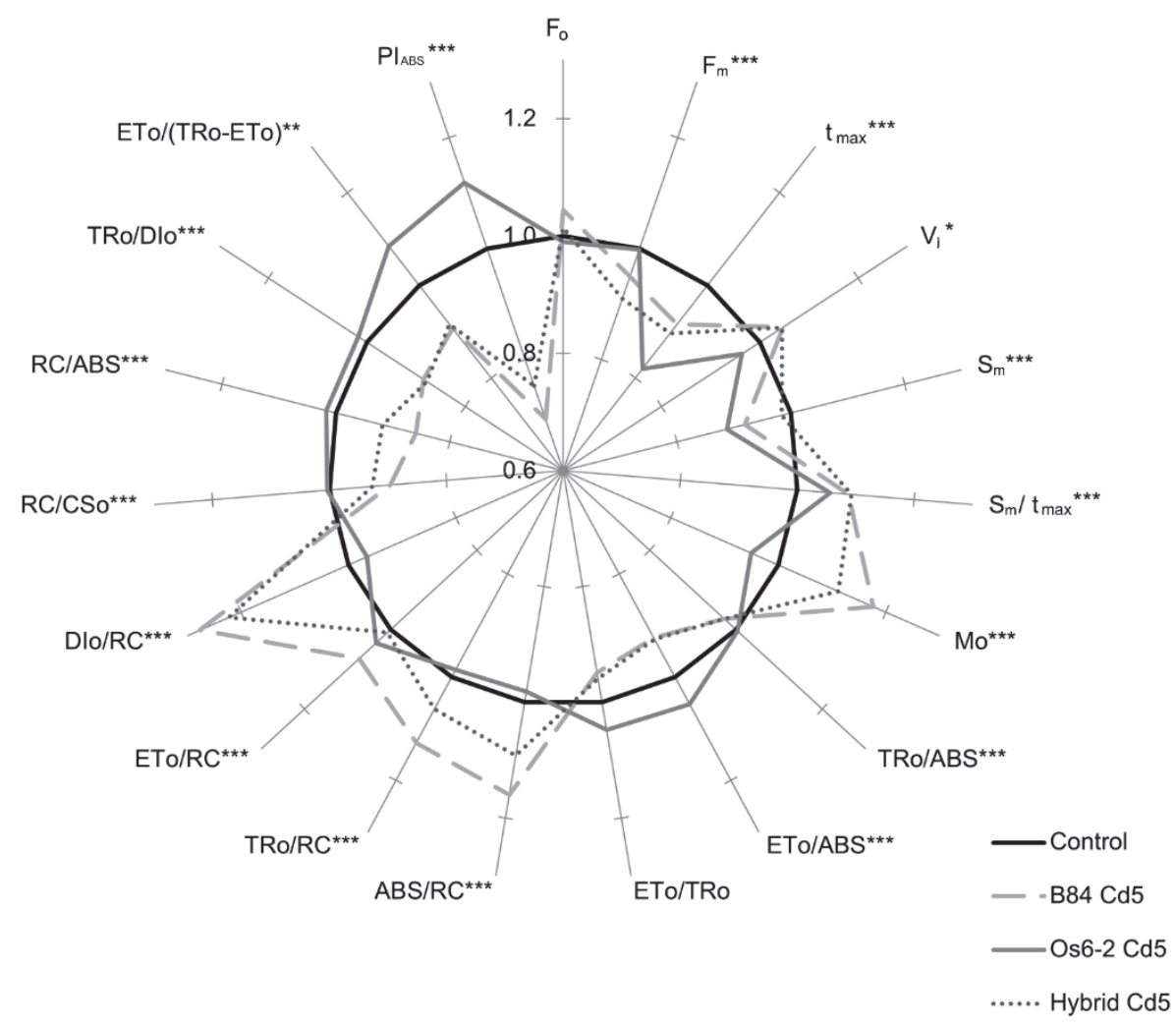

Fig. 2. Effects of elevated cadmium concentration in soil $\left[5 \mathrm{mg}(\mathrm{Cd}) \mathrm{kg}^{-1}\right.$ (soil)] on selected functional and structural JIP-test parameters plotted (radar plot center $=0.6$, maximum $=1.3$ ) relative to their respective controls (set as reference black circle $=1.0)$. Values represent averages $(n=45){ }^{*}, * * * * *$ represent significant differences between control and $\mathrm{Cd} 5$ treatment at $0.05,0.01$, and 0.001 , respectively. For definitions, formulas and abbreviations see also Table 2S. 
control. Difference in patterns of stressed and control plants pointed out the impact of elevated $\mathrm{Cd}$ content in soil on each genotype. ANOVA for selected biophysical parameters showed significant effects and main sources of variation (treatment, genotype), as well as their interactions. Differences between $\mathrm{CK}$ and $\mathrm{Cd} 5$ treatment were confirmed (Table 1S, supplement available online). Effect of $\mathrm{Cd}$ treatment was not significant only for $\mathrm{ET}_{\mathrm{o}} / \mathrm{TR}_{\mathrm{o}}$, while for all other parameters, effect of treatment was significant at $P<0.01$ and in some parameters at $P<0.001$. The effect of the genotype was significant for all selected parameters. Interactions of main effects were significant for all selected parameters (Fig. 2). Values of directly measured parameters $\left(\mathrm{F}_{\mathrm{m}}, \mathrm{t}_{\mathrm{max}}\right)$ showed a decrease caused by excess $\mathrm{Cd}$ content. B84 and hybrid values of $\mathrm{F}_{\mathrm{m}}$ parameter decreased, while Os6-2 did not change compared with CK (Table 1S). Values of $t_{\max }$ in $\mathrm{Cd} 5$ treatment decreased in all three genotypes, Os6-2 value being the lowest one. Relative variable fluorescence at $\mathrm{J}$ step $\left(\mathrm{V}_{\mathrm{J}}\right)$ increased in $\mathrm{B} 84$ and hybrid after the $\mathrm{Cd} 5$ treatment, while it was reduced in Os6-2. Normalized total complementary area above the transient curve $\left(\mathrm{S}_{\mathrm{m}}\right)$ declined in Cd5 treatment for B84 and Os6-2, while it did not change in hybrid. Initial rate of primary photochemistry $\left(\mathrm{M}_{\mathrm{o}}\right.$ - initial slope) increased in $\mathrm{Cd} 5$ treatment for B84 and hybrid, but it was reduced in Os6-2 line. The $\mathrm{Cd} 5$ treatment caused the highest impact on dissipation per reaction center $\left(\mathrm{DI}_{\mathrm{o}} / \mathrm{RC}\right)$; $\mathrm{B} 84$ line and hybrid increased levels of dissipation, while Os6-2 was not affected. Both hybrid and B84 line showed elevated values of absorption per reaction center (ABS/RC) and trapping per reaction center $\left(\mathrm{TR}_{\mathrm{o}} / \mathrm{RC}\right)$ after $\mathrm{Cd} 5$ treatment, while Os6-2 line was not affected. Increase of electron transport per reaction center $\left(\mathrm{ET}_{\mathrm{o}} / \mathrm{RC}\right)$ occurred in $\mathrm{B} 84$ and Os6-2 line, while the hybrid was unaffected by the $\mathrm{Cd} 5$ treatment. Density of reaction centers on Chl $a$ basis (RC/ABS) and density of reaction centers per excited cross-section $\left(\mathrm{RC} / \mathrm{CS}_{\mathrm{o}}\right)$ decreased in $\mathrm{B} 84$ line and hybrid after the $\mathrm{Cd} 5$ treatment, while Os6-2 line was unaffected. Maximum quantum yield of primary photochemistry (TRo/ABS) decreased after the $\mathrm{Cd} 5$ treatment in B84 and hybrid and was more or less unaffected in Os6-2 line. Maximum yield of electron transport (ETo/ABS) and efficiency of a trapped exciton to move an electron into the electron transport chain further than $\mathrm{Q}_{\mathrm{A}}^{-}\left(\mathrm{ET}_{\mathrm{o}} / \mathrm{TR}_{\mathrm{o}}\right)$ decreased both in B84 and hybrid after the $\mathrm{Cd} 5$ treatment and increased in Os6-2 line. Flux ratio trapping per dissipation $\left(\mathrm{TR}_{\mathrm{o}} / \mathrm{DI}_{\mathrm{o}}\right)$ decreased in the $\mathrm{Cd} 5$ treatment for B84 and hybrid, while it slightly increased in Os6-2 line. Electron transport beyond $\mathrm{Q}_{\mathrm{A}}^{-}\left[\mathrm{ET}_{\mathrm{o}}\left(\mathrm{TR}_{\mathrm{o}}-\mathrm{ET}_{\mathrm{o}}\right)\right]$ decreased in $\mathrm{B} 84$ and hybrid in $\mathrm{Cd} 5$ treatment and increased in Os6-2 line. Performance index on absorption basis ( $\mathrm{PI}_{\mathrm{ABS}}$ ) decreased in $\mathrm{B} 84$ and hybrid and increased in Os6-2 line after the $\mathrm{Cd} 5$ treatment.

Photosynthetic pigments and DM: In control treatment, DM was the lowest in B84 line, while Os6-2 and hybrid had similar values. $\mathrm{Cd}$ treatment caused an increase of DM

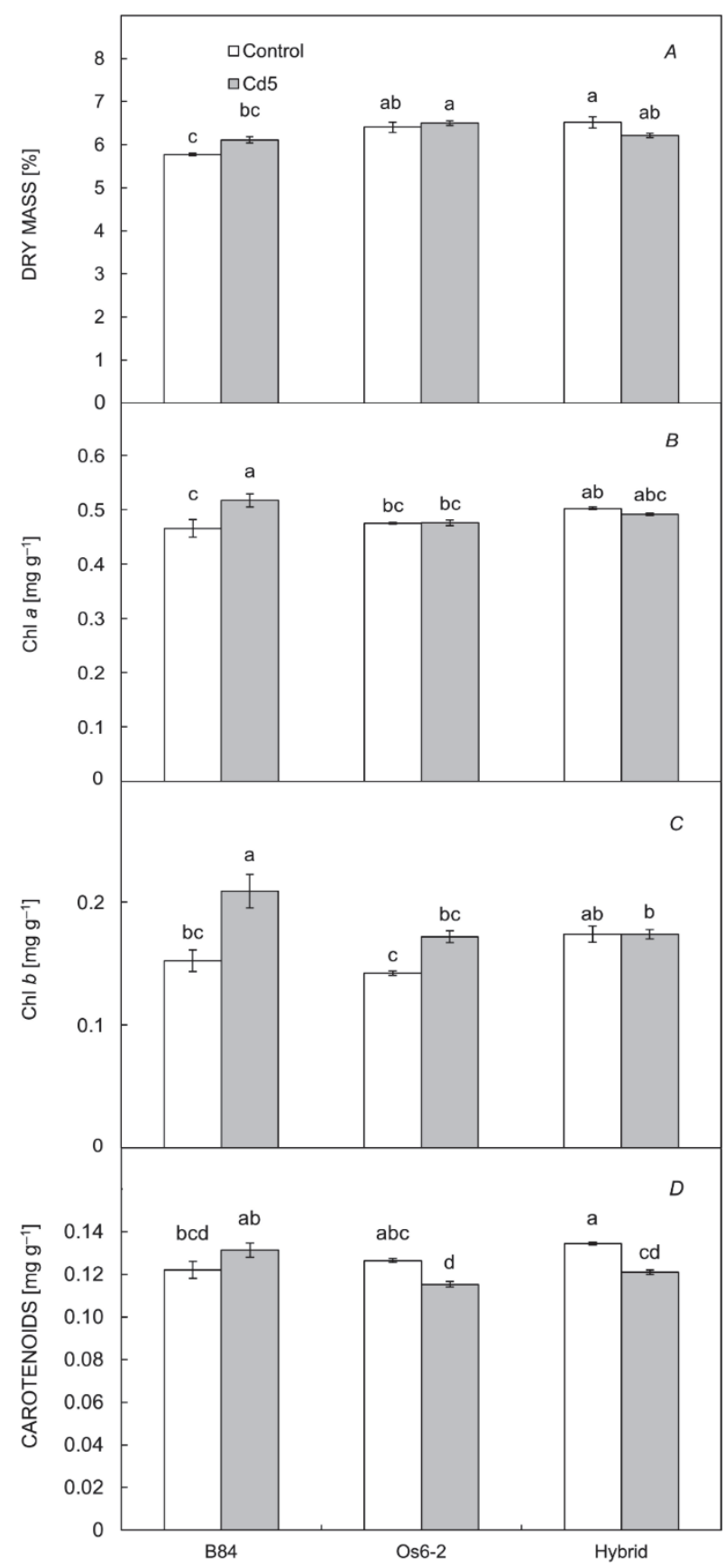

Fig. 3 Effects of elevated cadmium concentration in soil [5 mg(Cd) $\mathrm{kg}^{-1}$ (soil)] on dry mass $(A)$, chlorophyll (Chl) $a$ content $(B)$, Chl $b$ content $(C)$, and carotenoid content $(D)$. Means $( \pm \mathrm{SE}, n=9)$ with the same letters are not significantly different (Tukey's HSD 0.05 ).

in B84 and Os6-2 lines and in hybrid (Fig. 3A). ANOVA showed that there was no significant effect of the treatment, although genotype and genotype $\times$ treatment interaction showed significant effects (Table 1). Spectrophotometric data for Chls and Car revealed changes in pigment concentrations induced by $\mathrm{Cd}$ which were genotype dependent. In $\mathrm{CK}$, hybrid had the highest concentration of Chl $a, \mathrm{Chl} b$, and Car, while after the $\mathrm{Cd} 5$ 
Table 1. Analysis of variance for the effects of cadmium in soil and genotype on hydrogen peroxide $\left(\mathrm{H}_{2} \mathrm{O}_{2}\right)$, dry mass (DM), antioxidant enzymes, thiobarbituric acid reactive substances (TBARS), and photosynthetic pigments. APX - ascorbate peroxidase; POD - guaiacol peroxidase; CAT - catalase; Chl - chlorophyll; Car - carotenoids. n.s. - insignificant; $*, * *, * * *$ - significant differences between control and $\mathrm{Cd} 5$ treatment at $0.05,0.01$, and 0.001 levels, respectively.

\begin{tabular}{lllllllllll}
\hline $\begin{array}{l}\text { Source of } \\
\text { variation }\end{array}$ & df & $\mathrm{H}_{2} \mathrm{O}_{2}$ & DM & APX & POD & CAT & TBARS & Chl $a$ & Chl $b$ & Car \\
\hline Cd & 1 & $*$ & n.s. & $* * *$ & $* * *$ & $*$ & n.s. & $*$ & $* * *$ & $* *$ \\
Genotype & 2 & $* * *$ & $* * *$ & $* * *$ & $* * *$ & $* * *$ & $* * *$ & $*$ & $* *$ & $* *$ \\
Cd $\times$ Gen & 2 & $* * *$ & $* *$ & $* * *$ & n.s. & $* * *$ & $* * *$ & $* *$ & $* * *$ & $* * *$ \\
\hline
\end{tabular}

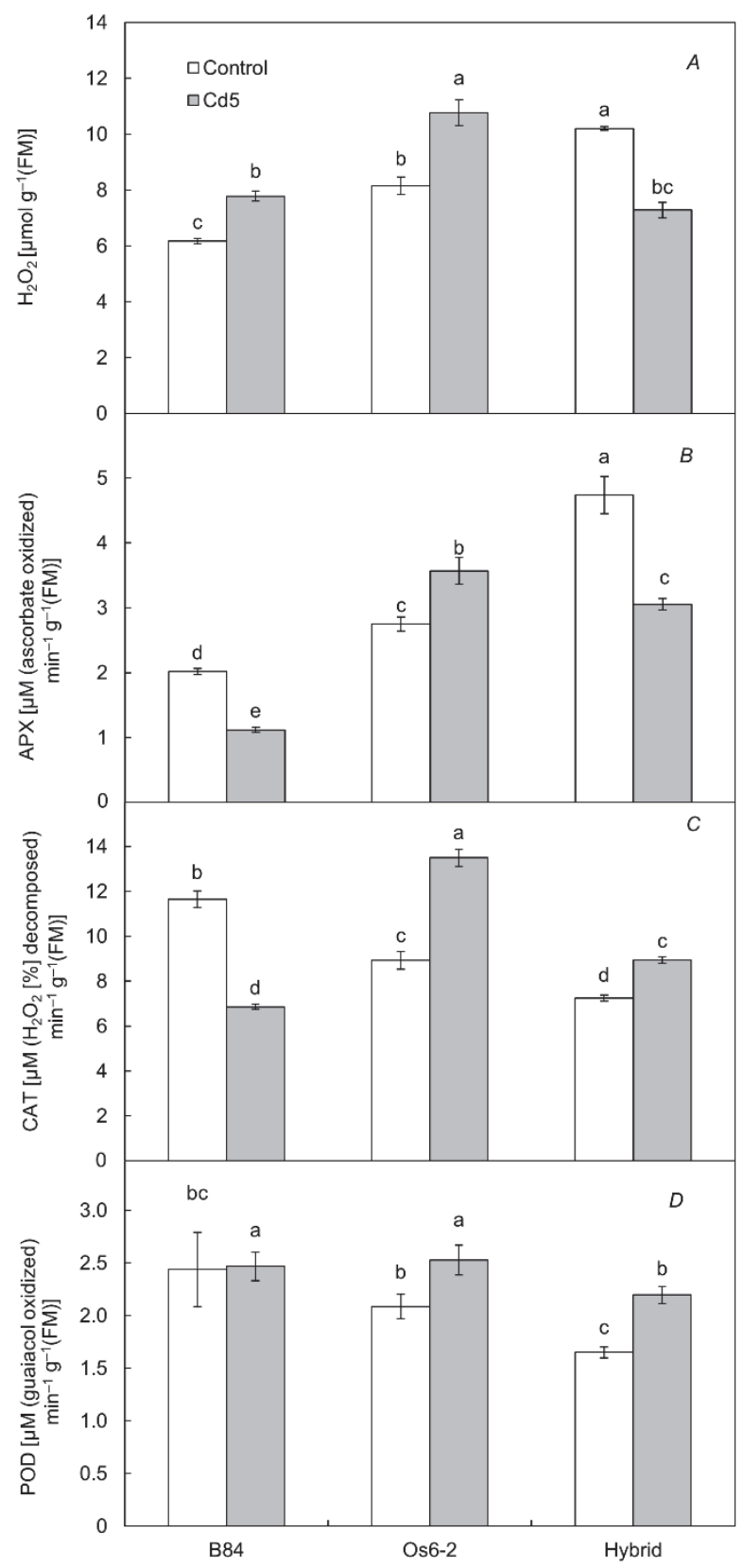

Fig. 4. Effects of elevated cadmium concentration in soil $\left[5 \mathrm{mg}(\mathrm{Cd}) \mathrm{kg}^{-1}\right.$ (soil)] on hydrogen peroxide $\left(\mathrm{H}_{2} \mathrm{O}_{2}\right)(A)$, ascorbate peroxidase (APX) $(B)$, catalase (CAT) $(C)$, and guaiacol peroxidase (POD) $(D)$. Means $( \pm \mathrm{SE}, n=9)$ with the same letters are not significantly different (Tukey's HSD 0.05$)$.

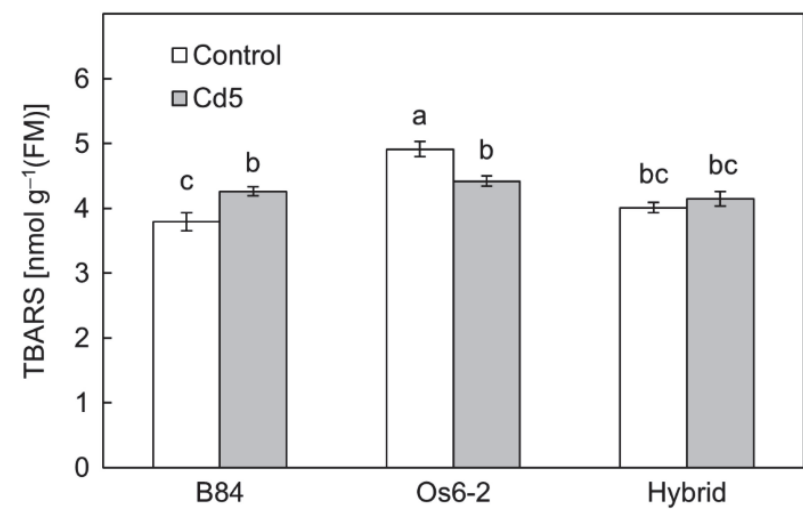

Fig. 5 Effects of elevated cadmium concentration in soil $\left[5 \mathrm{mg}(\mathrm{Cd}) \mathrm{kg}^{-1}\right.$ (soil)] on thiobarbituric acid-reactive substances (TBARS). Means ( $\pm \mathrm{SE}, n=9)$ with the same letters are not significantly different (Tukey's HSD 0.05 ).

treatment, B84 line had the highest values of measured pigments (Fig. $3 B-D$ ). The $\mathrm{Cd} 5$ treatment caused an increase in Chl $a$ and $b$ in B84 line, while in Os6-2, the increase was evident only in $\mathrm{Chl} b$, and in hybrid only in Chl $a$. The Car content was the highest in hybrid during the $\mathrm{CK}$ treatment. In $\mathrm{Cd} 5$ treatment, Car concentration increased in B84 line, while it decreased in Os6-2 and hybrid (Fig. 3D). ANOVA for Chl $a, \mathrm{Chl} b$, and Car proved significant effects for main sources of variation and their interactions (Table 1).

Antioxidant enzymes activity, TBARS content and $\mathrm{H}_{2} \mathrm{O}_{2}$ concentration: $A N O V A$ showed significant effects for main sources of variation and their interactions in all measured parameters except for interaction in POD and treatment in TBARS (Table 1). APX activity in control treatment was the highest in hybrid and the lowest in B84 line, while in $\mathrm{Cd} 5$ treatment it was the highest in Os6-2 line and the lowest in B84 line. Cd treatment resulted in a decrease of APX activity in B84 line and hybrid, while its activity increased in Os6-2 line (Fig. 4B). CAT activity in $\mathrm{CK}$ treatment was the highest in B84 line and the lowest one in hybrid. In Cd5 treatment, Os6-2 had the highest values, while B84 had the lowest values. $\mathrm{Cd}$ treatment caused decrease in CAT activity in B84 line, while it caused an increase in CAT activity in other two genotypes (Fig. 4C). POD activity in CK treatment was the highest in Os6-2 line and the lowest one in hybrid. Hybrid had the 
lowest value in $\mathrm{Cd} 5$ treatment, while there was no difference between B84 and Os6-2. The Cd5 treatment caused the same increasing POD activity trend for all three genotypes (Fig. 4D). TBARS content in CK was the highest in Os6-2 line, while after Cd treatment, no differences were found between three genotypes. In general, $\mathrm{Cd}$ treatment caused increase of TBARS content only in B84, while it caused a decrease in TBARS content in Os6-2. In hybrid,

\section{Discussion}

Inbred lines used in this study have been shown to differ in their respective ionomic profiles (Brkić et al. 2003, Sorić et al. 2011, Šimić et al. 2012) as well as in leaf Cd accumulation affinity (Sorić et al. 2009), B84 being a low, and Os6-2 high Cd accumulator, and their respective hybrid being intermediate (Franić et al. 2013). Mo17 was also designated as a high $\mathrm{Cd}$ accumulator elsewhere (Zhang et al. 2012) and shown similar in accumulation to Os6-2 (Franić et al. 2013). Soil Cd content of $5 \mathrm{mg}$ $\mathrm{kg}^{-1}$ (soil) was used as the middle value from da Silva et al. (2012) which caused visual symptoms of phytotoxicity. If calculated per volume of substrate, the content of applied $\mathrm{Cd}$ equals $2 \mathrm{mg} \mathrm{L}^{-1}$. The $\mathrm{Cd} 5$ treatment caused a decrease in $\mathrm{F}_{\mathrm{m}}$ in all three genotypes. Decrease in $\mathrm{F}_{\mathrm{m}}$ (Fig. 2), increase in $\mathrm{F}_{0}$ (although our results showed increase in $\mathrm{F}_{0}$, ANOVA showed it was not significant between treatments, data not shown) and the accompanying decrease in $\mathrm{F}_{\mathrm{v}} / \mathrm{F}_{\mathrm{m}}$ have been previously observed in maize cultivars exposed to $\mathrm{Cd}$ (Ekmekçi et al. 2008). Increase of $\mathrm{F}_{0}$ with increased $\mathrm{Cd}$ content in soil can be attributed to a reduction in energy transfer from antennae to the reaction center (Ralph and Burchett 1998) and the decrease of $F_{m}$ with increased $C d$ content in soil indicates changes in ultrastructure of thylakoid membranes that affects electron transport rate (Ekmekçi et al. 2008). The $\mathrm{t}_{\max }$ was reduced in $\mathrm{Cd} 5$ treatment in all three genotypes. The $t_{\max }$ is used to indicate the time at which $F_{m}$ is reached, and the reduction in $t_{\max }$ indicates stress. Since it is accepted that $F_{m}$ expresses the state of PSII at which all $\mathrm{Q}_{\mathrm{A}}$ are reduced (Mallick and Mohn 2003), the decrease in $t_{\max }$ suggests that the pool of $\mathrm{Q}_{\mathrm{A}}$ available for reduction decreased. Increase in $\mathrm{V}_{\mathrm{J}}$ parameter in B84 and hybrid suggests the decrease in efficiency of $\mathrm{Q}_{\mathrm{A}}^{-}$reoxidation (accumulation of reduced $\mathrm{Q}_{\mathrm{A}}{ }^{-}$), since $\mathrm{V}_{\mathrm{J}}$ is a measure of the fraction of reduced $\mathrm{Q}_{\mathrm{A}}{ }^{-}$ (Strasser et al. 2000, Havaux and Strasser 1992, Kalaji et al. 2014). $\mathrm{S}_{\mathrm{m}}$ is proportional to the number of electrons that pass through the electron transport chain (Stirbet and Govindjee 2011). Decrease in $\mathrm{S}_{\mathrm{m}}$ in B84 and Os6-2 lines suggests that maximum fluorescence could be reached quicker because fewer electrons are needed to reduce PSII electron acceptors which can be also seen through a decrease of $t_{\max }$ parameter. Initial slope of the relative variable fluorescence $\left(\mathrm{M}_{\mathrm{o}}\right)$ corresponds to relative rate of $\mathrm{Q}_{\mathrm{A}}$ reduction; it increased in B84 and hybrid (and was reduced in Os6-2). It has been shown previously that $\mathrm{M}_{\mathrm{o}}$ is increased in stressed plants (Christen et al. 2007). there was no difference between treatments (Fig. 5). $\mathrm{H}_{2} \mathrm{O}_{2}$ concentration in $\mathrm{CK}$ treatment was the highest one in hybrid, while it was the highest in Os6-2 line after the $\mathrm{Cd} 5$ treatment. B84 line had the lowest value in CK, while hybrid had the lowest value after the $\mathrm{Cd} 5$ treatment. The $\mathrm{Cd}$ treatment caused and increase in $\mathrm{H}_{2} \mathrm{O}_{2}$ concentration in both lines (B84, Os6-2), while it caused a decrease in $\mathrm{H}_{2} \mathrm{O}_{2}$ concentration in hybrid (Fig. 4A).

Negative effects of $\mathrm{Cd} 5$ treatment were evident in the decrease of quantum yields of PSII electron transport and the efficiency of excitation energy capture by open PSII reaction centers $\left(\mathrm{TR}_{\mathrm{o}} / \mathrm{ABS}, \mathrm{ET}_{\mathrm{o}} / \mathrm{ABS}\right.$, and $\left.\mathrm{ET}_{\mathrm{o}} / \mathrm{TR}_{\mathrm{o}}\right)$. Decreases in acceptor side-dependent yields $\left(\mathrm{ET}_{\mathrm{o}} / \mathrm{ABS}\right.$, $\mathrm{ET}_{\mathrm{o}} / \mathrm{TR}_{\mathrm{o}}$ ), which describe the efficiency of electron transport, suggested photoinhibitory damage to PSII caused by excess $\mathrm{Cd}$ which has been observed in earlier studies (Pagliano et al. 2006). Decrease in $\mathrm{TR}_{\mathrm{o}} / \mathrm{ABS}$ caused by heavy metal exposure has been reported previously (Jiang et al. 2008, Turnau et al. 2008) and has been attributed to photoinhibition caused by excess of heavy metals. Increase in ABS/RC, which was observed in B84 and hybrid in $\mathrm{Cd} 5$ treatment, suggests that a fraction of active reaction centers was inactivated or that the apparent antenna size increased (Lichtenthaler et al. 1982). These changes were confirmed by decreases in $\mathrm{RC} / \mathrm{CS}_{\mathrm{o}}$ and $\mathrm{RC} / \mathrm{ABS}$. Inactivation of reaction centers can be an indication of susceptibility to photoinhibition, and the inactivation is a downregulation mechanism of dealing with excess of absorbed light. Increase in trapping per RC $\left(\mathrm{TR}_{\mathrm{o}} / \mathrm{RC}\right)$ can indicate impairment of the oxygen evolving complex (Kalaji et al. 2014) and was observed under Cd treatment in the same genotypes. Most notable deviation from the control values was observed in the energy dissipation $\left(\mathrm{DI}_{\mathrm{o}} / \mathrm{RC}\right)$. Energy dissipation is enhanced to protect leaves from photo-oxidative damage; increased dissipation suggests that absorbed energy was dissipated instead of utilized to reduce $\mathrm{Q}_{\mathrm{A}}^{-}$. Dissipation of excess absorbed light by heat has been previously shown in heavy metal treated plants, including Cd (Zhou et al. 2005, Begović et al. 2016). $\mathrm{PI}_{\mathrm{ABS}}$ is calculated as (RC/ABS) $\left(\mathrm{TR}_{\mathrm{o}} / \mathrm{ABS}-\mathrm{TR}_{\mathrm{o}}\right)\left(\mathrm{ET}_{\mathrm{o}} / \mathrm{TR}_{\mathrm{o}}-\mathrm{ET}_{\mathrm{o}}\right)$. Higher $\mathrm{PI}_{\mathrm{ABS}}$ (or plant "vitality") under $\mathrm{Cd} 5$ treatment in Os6-2 genotype occurred due to the increase in all three parameters but the highest impact on $\mathrm{PI}_{\mathrm{ABS}}$ was from $\mathrm{ET}_{\mathrm{o}} /\left(\mathrm{TR}_{\mathrm{o}}-\mathrm{ET}_{\mathrm{o}}\right)$ suggesting $\mathrm{Cd}$ treatment might have caused an increase in $\mathrm{CO}_{2}$ assimilation in Os6-2 line since a relationship between photosynthetic electron transport and $\mathrm{CO}_{2}$ assimilation has been established (Krall et al. 1992), although the increase of electron transport can be also related to other biochemical pathways (Kalaji et al. 2016). Higher $\mathrm{PI}_{\mathrm{ABS}}$ also suggests better overall photosynthetic performance. Decrease in $\mathrm{PI}_{\mathrm{ABS}}$ at $\mathrm{Cd} 5$ treatment in $\mathrm{B} 84$ and hybrid was caused by a decrease of all three components of $\mathrm{PI}_{\mathrm{ABS}}$, but it can be seen that lower $\mathrm{PI}_{\mathrm{ABS}}$ 
value in $\mathrm{B} 84$ is the result of lower $\mathrm{RC} / \mathrm{ABS}$ value suggesting that a larger proportion of reaction centers was inactivated in B84 line than in hybrid. Decrease in $\mathrm{PI}_{\mathrm{ABS}}$ has been previously shown to be negatively affected by heavy metals (Begović et al. 2016, Żurek et al. 2014). Although $\mathrm{PI}_{\mathrm{ABS}}$ and most of other fluorescence parameters did not show Cd-induced stress in Os6-2 inbred, some other parameters revealed stress, such as decrease in $t_{\max }$ and $\mathrm{S}_{\mathrm{m}}$ which suggested that Os6-2 is more tolerant to Cd-induced stress at this stage probably as a result of higher resistance to $\mathrm{Cd}$ (or due to lower $\mathrm{Cd}$ uptake) as proposed by Kalaji et al. (2007, 2010).

The Chl $a$ content increase was followed by increase in some corresponding fluorescence parameters, such as $\mathrm{F}_{0}$, $F_{150}$, and $F_{300}$, but stress in B84 line was revealed through malfunction of photosystem components detected by increase in dissipation of energy per $\mathrm{RC}$, as well as with the decrease in $\mathrm{TR}_{0} / \mathrm{DI}_{\mathrm{o}}$ (Strasser 2000). Elevated contents of Chl $a$ in $\mathrm{B} 84$ after the $\mathrm{Cd} 5$ treatment might be a result of stress adaptation, reaction of young leaves to Cd stress (Drążkiewicz et al. 2003, Chaneva et al. 2010) or Cd content in substrate was simply too low to induce stress for all the physiological traits (Chaneva et al. 2010). Same authors (Chaneva et al. 2010) obtained comparable results in young maize plants also for $\mathrm{Chl} a / b$ ratio which decreased in both inbreds, as well as for $\mathrm{F}_{\mathrm{v}} / \mathrm{F}_{\mathrm{m}}$ and $\mathrm{F}_{\mathrm{v}} / \mathrm{F}_{0}$ values (results not shown) which were not affected in hybrid. Similar results for Chl contents were shown in dill plants (Aghaz and Bandehagh 2013). Hydrogen peroxide contents increased in both inbreds after the Cd5 treatment, while the treatment caused its decline in hybrid, although hybrid had significantly the highest concentration of peroxide in CK which is in accordance with results of De Gara et al. (2000) and is probably related to heterosis effect. We obtained comparable results in CK for APX and CAT activities as well. High production of ROS is related to $\mathrm{Cd}$ accumulation and since $\mathrm{Cd}$ cannot take a part in Fenton-type reactions, its effects on peroxide-generating mechanisms are yet to be elucidated (Rodríguez-Serrano et al. 2009). Effect of the Cd5 treatment on hydrogen peroxide enhancement was observed in both inbreds, although it was more pronounced in Os6-2, which was designated as an accumulator, while peroxide contents in hybrid were lowered by the treatment. Similar results were shown by Anjum et al. (2015) in young maize plants of two cultivars differing in Cd uptake. As hydrogen peroxide causes lipid peroxidation in maize leaves (Procházková et al. 2001), CAT (Ci et al. 2009) and APX (Anjum et al. 2015) activities are related to its accelerated production

\section{References}

Aebi H.: Catalase in vitro. - Methods Enzymol. 105: 121-126, 1984.

Aghaz M., Bandehagh A.: Phytotoxic effects of cadmium on photosynthesis pigments in dill (Anethum graveolens). - Int. J. Farm. Alli. Sci. 2: 544-548, 2013. and cultivars showing their lower activities can be considered Cd-sensitive. Contents of TBARS, a direct product of lipid peroxidation, were significantly elevated in B84 line, which is in agreement with lower APX and CAT activities alleviated by the $\mathrm{Cd} 5$ treatment, as these two enzymes are most important plant cellular mechanism for hydrogen peroxide detoxification (Asada 1992, Cakmak et al. 1993). Decrease in TBARS in Os6-2 inbred could be attributed to positive effect of the $\mathrm{Cd} 5$ treatment on all measured antioxidant enzyme activities. Elevated activities of enzymes probably lowered the deleterious effects of peroxide for lipids and proteins in Os6-2. There were no observed differences for TBARS in hybrid, although activity of APX was lowered by the $\mathrm{Cd} 5$ treatment. CAT and POD activities were slightly elevated but we suggest that $\mathrm{Cd}$ dose was too low to induce stress in hybrid because its high vigor due to heterosis caused a dilution effect (Chien and Menon 1996). Elevated POD activities caused by the $\mathrm{Cd} 5$ treatment in all genotypes generally agreed with results of Ekmekçi et al. (2008). Car are a group of pigments that act as nonenzymatic agent of ROS detoxification (Krinsky 1989). In our study, the increase of Car content was observed after the $\mathrm{Cd} 5$ treatment in B84 inbred line, while there was a significant decrease detected in Os6-2 and hybrid. Chaneva et al. (2010) obtained similar results with ascending trend for three $\mathrm{Cd}$ concentrations in young maize plants, similarly as B84 in our research, while Chaudhary and Sharma (2009) showed that the Car response to $\mathrm{Cd}$ was concentration-dependent.

According to examined parameters, inbred B84 was shown to be $\mathrm{Cd}$ sensitive at this particular growth stage, while Os 6-2 did not appear to be negatively affected by $\mathrm{Cd}$ treatment. In B84 line, the $\mathrm{Cd}$ treatment negatively affected most of measured parameters indicating problems during all stages of photosynthesis and overall oxidative status impairment. Although there was no stress detected in Os6-2 through decreasing antioxidant enzyme activity, declines in Chl $a$ fluorescence parameters such as $\mathrm{t}_{\max }$ and $\mathrm{S}_{\mathrm{m}}$ indicated stress. Probably due to a dilution effect, there was no or very weak $\mathrm{Cd}$ stress detectable through antioxidant enzyme activities or hydrogen peroxide content in hybrid. Although, stress was detected through Chl $a$ fluorescence, where the response of hybrid was similar to B84 but of lesser intensity. In this study, chlorophyll $a$ fluorescence was shown to be more sensitive method for Cd-stress detection than biochemical parameters examined and our results showed these methods as complementary to each other.
Anjum S.A., Tanveer M., Hussain S. et al.: Cadmium toxicity in maize (Zea mays L.): consequences on antioxidative systems, reactive oxygen species and cadmium accumulation. Environ. Sci. Pollut. R. 22: 17022-17030, 2015.

Asada K.: Ascorbate peroxidase - a hydrogen peroxide-scaven- 
ging enzyme in plants. - Physiol. Plantarum 85: 235-241, 1992.

Begović L., Mlilnarić S., Antunović Dunić J. et al.: Response of Lemna minor L. to short-term cobalt exposure: The effect on photosynthetic electron transport chain and induction of oxidative damage. - Aquat. Toxicol. 175: 117-126, 2016.

Brkić I., Šimić D., Zdunić Z. et al.: Combining abilities of cornbelt inbred lines of maize for mineral content in grain. Maydica 48: 293-297, 2003.

Burzyński M., Żurek A.: Effects of copper and cadmium on photosynthesis in cucumber cotyledons. - Photosynthetica 45: 239-244, 2007.

Cakmak I., Štrbac D., Marchner H.: Activities of hydrogen peroxide-scavenging enzymes in germinating wheat seeds. $-\mathrm{J}$. Exp. Bot. 44: 127-132, 1993.

Chaneva G., Parvanova P., Tzvetkova N., Uzunova A.: Photosynthetic response of maize plants against cadmium and paraquat impact. - Water Air Soil Pollut. 208: 287-293, 2010.

Chaoui A., Mazhoudi S., Habib Ghorbal M., El Ferjani E.: Cadmium and zinc induction of lipid peroxidation and effects on antioxidant enzyme activities in bean (Phaseolus vulgaris L.). - Plant Sci. 127: 139-147, 1997.

Chaudhary S., Sharma Y.K.: Interactive studies of potassium and copper with cadmium on seed germination and early seedling growth in maize (Zea mays L.). - J. Environ. Biol. 30: 427-432, 2009.

Chien S.H., Menon R.G.: Dilution effect of plant biomass on plant cadmium concentration ad induced by application of phosphate fertilizers. - In: Rodriguez-Barrueco C. (ed.): Fertilizers and Environment. - Development in Plant and Soil Sciences. Pp. 437-442. Kluwer Academic Publishers, Dordrecht 1996.

Cho U.H., Seo N.H.: Oxidative stress in Arabidopsis thaliana exposed to cadmium is due to hydrogen peroxide accumulation. - Plant Sci. 168: 113-120, 2005.

Christen D., Schönmann S., Jermini M. et al.: Characterization and early detection of grapevine (Vitis vinifera) stress responses to esca disease by in situ chlorophyll fluorescence and comparison with drought stress. - Environ. Exp. Bot. 60: 504-514, 2007.

Ci D., Jiang D., Dai T. et al.: Effects of cadmium on plant growth and physiological traits in contrast wheat recombinant inbred lines differing in cadmium tolerance. - Chemosphere 77: 1620$1625,2009$.

Da Silva A.J., Nascimento C.W.A., Gouveia-Neto A.S., da SilvaJr E.A.: LED induced chlorophyll fluorescence spectral analysis for the early detection and monitoring of cadmium toxicity in maize plants. - Water Air Soil Pollut. 223: 35273533, 2012.

Das P., Samantaray S., Rout R.: Studies on cadmium toxicity in plants: a review. - Environ. Pollut. 98: 29-36, 1998.

De Gara L., Paciolla C., De Tullio M. et al.: Ascorbate-dependent hydrogen peroxide detoxification and ascorbate regeneration during germination of a highly productive maize hybrid: Evidence of an improved detoxification mechanism against reactive oxygen species. - Physiol. Plantarum 109: 7-13, 2000.

Di Cagno R., Guidi L., Stefani A., Soldatini G.F.: Effects of cadmium on growth of Heliantus annus seedlings: physiological aspects. - New Phytol. 144: 65-71, 1999.

Di Toppi L.S., Gabbrielli R.: Response to cadmium in higher plants. - Environ. Exp. Bot. 41: 105-130, 1999.

Drążkiewicz M., Tukendorf A., Baszyński T.: Age dependent response of maize leaf segments to cadmium treatment: Effect on chlorophyll fluorescence and phytochelatin accumulation. -
J. Plant Physiol. 160: 247-254, 2003.

Ekmekçi Y., Tanyolaç D., Ayhan B.: Effects of cadmium on antioxidant enzyme and photosynthetic activities in leaves of two maize cultivars. - J. Plant Physiol. 165: 600-611, 2008

Florijn P.J., van Beusichem M.L.: Uptake and distribution of cadmium in maize inbred lines. - Plant Soil 150: 25-32, 1993.

Franić M., Sorić R., Lončarić Z. et al.: Genotype variations in maize on cadmium contaminated soil. - In: Jug I., Đurđević B. (ed.): Proceedings of $6^{\text {th }}$ Conference Agriculture in Nature and Environment Protection. Pp. 113-117. Glas Slavonije d.d., Osijek 2013.

Gallego S.M., Pena L.B., Barcia R.A. et al.: Unraveling cadmium toxicity and tolerance in plants: insight into regulatory mechanisms. - Environ. Exp. Bot. 83: 33-46, 2012.

Grant C.A., Buckley W.T., Bailey L.D., Selles F.: Cadmium accumulation in crops. - Can. J. Plant Sci. 78: 1-17, 1998.

Havaux M., Strasser R.J.: Dynamics of electron transfer within and between PS II reaction center complexes indicated by the light-saturation curve of in vivo variable chlorophyll fluorescence emission. - Photosynth. Res. 31: 149-156, 1992.

Jiang H.-X., Chen L.-S., Zheng J.-G. et al.: Aluminium-induced effects on photosystem II photochemistry in citrus leaves assessed by chlorophyll a fluorescence transient. - Tree Physiol. 28: 1863-1871.

Krall J.P., Edwards G.E.: Relationship between photosystem II activity and $\mathrm{CO} 2$ fixation in leaves. - Physiol. Plantarum 86: 180-187, 1992

Kalaji H.M.; Loboda T.: Photosystem II of barley seedlings under cadmium and lead stress. - Plant Soil Environ. 53: 511-516, 2007.

Kalaji H M, Oukarroum A, Alexandrov V et al.: Identification of nutrient deficiency in maize and tomato plants by in vivo chlorophyll $a$ fluorescence measurements. - Plant. Physiol. Bioch. 81: 16-25, 2014

Kalaji H.M., Schansker G., Breštić M. et al.: Frequently asked questions about chlorophyll fluorescence, the sequel. Photosynth. Res.: doi: 10.1007/s11120-016-0318-y, 2016.

Krantev A., Yordanova R., Janda T. et al.: Treatment with salicylic acid decreases the effect of cadmium on photosynthesis in maize plants. - J. Plant Physiol. 165: 920931, 2008.

Krinsky N.: Antioxidant functions of carotenoids. - Free Radical Bio. Med. 7: 617-635, 1989.

Küpper H., Küpper F., Spiller M.: Environmental relevance of heavy metal-substituted chlorophylls using the example of water plants. - J. Exp. Bot. 47: 259-266, 1996.

Larsson E.H., Bornman J.F., Asp H.: Influence of UV-B radiation and $\mathrm{Cd}^{2+}$ on chlorophyll fluorescence, growth and nutrient content in Brassica napus. - J. Exp. Bot. 49: 1031-1039, 1998

Lee E.A., Tracy W. F.: Modern maize breeding. - In: Bennetzen J., Hake, S. (ed.): Handbook of Maize: Genetics and Genomics. Pp. 141-160. Springer, New York 2009.

Lichtenthaler H.K., Kuhn G., Prenzel U. et al.: Adaptation of chloroplast-ultrastructure and of chlorophyll-protein levels to high-light and low-light growth conditions. $-\mathrm{Z}$. Naturforsch. 37: 464-475, 1982.

Lichtenthaler H.K.: Chlorophylls and carotenoids: pigments of photosynthetic biomembranes. - Methods Enzymol. 148: 350382, 1987.

Mallick N., Mohn F.H.: Use of chlorophyll fluorescence in metal-stress research: a case study with green microalga Scenedesmus. - Ecotox. Environ. Safe. 55: 64-69, 2003.

Nakano Y., Asada K.: Hydrogen peroxide is scavenged by 
ascorbate - specific peroxidase in spinach chloroplasts. - Plant Cell. Physiol. 22: 867-880, 1981.

Pagliano C., Raviolo M., Dalla Vecchia F. et al.: Evidence for PSII donor-side damage and photoinhibition induced by cadmium treatment on rice (Oryza sativa L.). - J. Photoch. Photobio. B 84: 70-78, 2006.

Procházková D., Sairam R.K., Srivastava G.C., Singh D.V.: Oxidative stress and antioxidant activity as the basis of senescence in maize leaves. - Plant Sci. 161: 765-771, 2001.

$\mathrm{R}$ Core Team. R: A language and environment for statistical computing. R Foundation for Statistical Computing, Vienna, Austria. ISBN 3-900051-07-0, URL http://www.Rproject.org/, 2012.

Ralph P.J., Burchett M.D.: Photosynthetic response of Halophila ovalis to heavy metal stress. - Environ. Pollut. 103: 91-101, 1998.

Rodríguez-Serrano M., Romero-Puertas M.C., Pazmiño D.M. et al.: Cellular response of pea plants to cadmium toxicity: cross talk between reactive oxygen species, nitric oxide, and calcium. - Plant Physiol. 150: 229-243, 2009.

Romero-Puertas M.C., Palm, J.M., Gómez M. et al.: Cadmium causes the oxidative modification of proteins in pea plants. Plant Cell Environ. 25: 677-686, 2002.

Sandalio L.M., Dalurzo H.C., Gómez M. et al.: Cadmiuminduced changes in the growth and oxidative metabolism of pea plants. - J. Exp. Bot. 52: 2115-2126, 2001.

Schützendübel A., Polle A.: Plant responses to abiotic stresses: heavy metal induced oxidative stress and protection by mycorrhisation. - J. Exp. Bot. 53: 1351-1365, 2002.

Siegel B.Z., Galston A.W.: The isoperoxidases of Pisum sativum. - Plant Physiol. 42: 221-226, 1967.

Šimić D., Mladenović Drinić S., Zdunić Z. et al.: Quantitative trait loci for biofortification in maize grain. - J. Hered. 103: 4754,2012

Sorić R., Ledenčan T., Zdunić Z. et al.: Quantitative trait loci for metal accumulation in maize leaf. - Maydica 56: 323-329, 2011.

Sorić R., Lončarić Z., Kovačević V. et al.: A major gene for leaf cadmium accumulation in maize (Zea mays L.). - In: The Proceedings of the International Plant Nutrition Colloquium XVI. http://escholarship. org/uc/item/1q48v6cf. UC Davis, 2009.

STAR, version 2.0.1. Biometrics and Breeding Informatics, PBGB Division, International Rice Research Institute. Los Baños, Laguna 2014.

Stirbet A, Govindjee: On the relation between the Kautsky effect (chlorophyll $a$ fluorescence induction) and photosystem II: Basics and applications of the OJIP fluorescence transient. - J.
Photoch. Photobio. B. 104: 236-257, 2011.

Strasser R.J., Srivastava A., Govindjee: Polyphasic chlorophyll $a$ fluorescence transient in plants and cyanobacteria. Photochem. Photobiol. 61: 32-42, 1995.

Strasser R.J., Srivastava A., Tsimilli-Michael M.: Analysis of chlorophyll $a$ fluorescence transient. - In: Papageorgiou G.C., Govindjee (ed.): Advances in Photosynthesis and Respiration. Pp. 321-362. Springer, Dodrecht 2004.

Strasser R.J., Srivastava A., Tsimilli-Michael M.: The fluorescent transient as a tool to characterize and screen photosynthetic samples. - In: Yunus M., Pathre, U., Mohanty P. (ed.): Probing Photosynthesis: Mechanisms, Regulation and Adaptation. Pp. 445-483. Taylor and Francis, London 2000.

Strasser R.J., Tsimilli-Michael M., Qiang S., Goltsev V.: Simultaneous in vivo recording of prompt and delayed fluorescence and $820-\mathrm{nm}$ reflection changes during drying and after rehydration of the resurrection plant Haberlea rhodopensis. Biochim. Biophys. Acta 1797: 1313-1326, 2010.

Tuba Z., Saxena D.K., Srivastava K., Kalaji M.H.: Chlorophyll $a$ fluorescence measurements for validating the tolerant bryophytes for heavy metal $(\mathrm{Pb})$ biomapping. - Curr. Sci. 98: 1505-1508, 2010.

Turnau K., Anielska T., Ryszka P. et al. Establishment of arbuscular mycorrhizal plants originating from xerothermic grasslands on heavy metal rich industrial wastes - new solution for waste revegetation. - Plant Soil 305: 267-280, 2008.

Velikova V., Yordanov I., Edreva A.: Oxidative stress and some antioxidant systems in acid-rain treated bean plants. Protective role of exogenous polyamines. - Plant Sci. 151: 59-66, 2000

Verbruggen N., Hermans C., Schat H.: Mechanisms to cope with arsenic or cadmium excess in plants. - Curr. Opin. Plant Biol. 12: 364-372, 2009.

Verma S., Dubey R.S.: Leads toxicity induces lipid peroxidation and alters the activities of antioxidant enzxmes in growing rice plants. - Plant Sci. 164: 645-655, 2003.

Weigel H.J.: Inhibition of photosynthetic reactions of isolated intact chloroplasts by cadmium. - J. Plant Physiol. 119: 179$189,1985$.

Zhang Z., Jin F., Wang C.: Differences between $\mathrm{Pb}$ and $\mathrm{Cd}$ accumulation in 19 elite maize inbred lines and application prospects. - J. Biomed. Biotechnol. 2012: 271485, 2012.

Zhou W., Qiu B.: Effects of cadmium hyperaccumulation on physiological characteristics of Sedum alfredii Hance (Crassulaceae). - Plant Sci. 169: 737-745, 2005.

Żurek G., Rybka K., Pogrzeba M. et al.: Chlorophyll $a$ fluorescence in evaluation of the effect of heavy metal soil contamination on perennial grasses. - PLOS ONE 9: e91475, 2014. 